\title{
A EDUCAÇÃO AMBIENTAL NAS ESCOLAS DA SERRA DA JIBOIA (BA): POSSIBILIDADES DE CONTRIBUIÇÕES COM O PROJETO DE EDUCAÇÃO DO CAMPO
}

Lilian Souza Santos ${ }^{1}$

Marcos Teixeira ${ }^{2}$

Resumo: Avaliamos a oferta da Educação Ambiental (EA) nas escolas localizadas nas zonas rurais de dois municípios da Região da Serra da JibóiaBA. Aplicamos um questionário misto para 45 professores de 11 escolas, participamos de reuniões de planejamento, visitamos as escolas para observações do cotidiano e realizamos entrevistas abertas com os professores. Todos os professores afirmaram trabalhar a EA inserida nas disciplinas e em projetos sendo que a principal concepção de EA observada foi a naturalista/comportamental. A deficiência de formação básica dos professores associada à ausência de uma formação para a compreensão dos princípios e objetivos da EA e da Educação do Campo, se apresenta como um problema a ser superado pela sociedade local. Tal realidade compromete 0 desenvolvimento de uma educação contextualizada com as especificidades do camponês e da biodiversidade da Região da Serra da Jiboia, onde a relação homem-natureza já sente os efeitos degradantes do modelo hegemônico de desenvolvimento econômico.

Palavras-chave: Educação; Meio Ambiente; Formação; Professores; Rural.

${ }^{1}$ Universidade Federal do Recôncavo da Bahia, Cruz das Almas, BA. E-mail: lilianscon@hotmail.com ${ }^{2}$ U Universidade Federal do Espírito Santo, São Mateus, ES. E-mail: marcosteixeiraufes@gmail.com Revbea, São Paulo, V.11, № 2: 385-399, 2016.

revista brasileira educação ambiental 


\title{
Introdução
}

A análise do histórico de construção dos projetos da Educação Ambiental e da Educação do Campo Brasileiro evidenciam diálogos e convergências entre essas duas áreas. Ambas nasceram dos movimentos sociais em contestação ao modelo de desenvolvimento vigente, que produz uma sociedade cada vez mais egoísta, injusta, socialmente excludente e ambientalmente insustentável. Nesse contexto, dois temas principais as aproximam: (1) o debate da relação sociedade-natureza, que se dá mediado pelas relações de trabalho e (2) o reconhecimento da necessidade de se repensar nossa relação com o mundo natural.

O projeto de Educação do Campo traz uma reflexão pedagógica que vê o campo como lugar que produz pedagogia através das relações que o homem e a mulher constroem entre eles e com a natureza para promover sua existência. No entendimento de Caldart (2009, p. 154)

\begin{abstract}
É um projeto de educação que reafirma, como grande finalidade da ação educativa, ajudar no desenvolvimento mais pleno do ser humano, na sua humanização e inserção crítica na dinâmica da sociedade de que faz parte; que compreende que os sujeitos se humanizam ou se desumanizam sob condições materiais e relações sociais determinadas; que nos mesmos processos em que produzimos a nossa existência nos produzimos como seres humanos; que as práticas sociais e, entre elas, especialmente as relações de trabalho conformam (formam ou deformam) os sujeitos (CALDART, 2009, p.154).
\end{abstract}

Portanto, na educação do campo o trabalho é visto como produção do conhecimento. Há uma intrínseca e inegável relação entre a educação e a produção material da vida que compreende os processos formativos como constituídos no âmbito das relações sociais, determinadas essencialmente pelo trabalho (MOLINA, 2010, p.131). Dessa forma, o trabalho é entendido como produção material e cultural da existência humana, pois é através dele que o homem transforma a natureza para poder sobreviver. $O$ trabalho se instaura a partir do momento em que seu agente antecipa mentalmente a finalidade da ação (SAVIANI, 1994, p.21).

Na medida em que, por meio de suas lutas, constroem outra sociedade, outro campo e outra história, os sujeitos se constroem, e são, portanto, sujeitos de sua própria transformação e libertação. É aqui, com a finalidade social do trabalho que a educação do campo inevitavelmente volta a dialogar com a Educação Ambiental. É quando trabalha que o homem explora e modifica o mundo natural e, ao mesmo tempo, explora ou tem sua natureza explorada por outro homem. É por meio das relações de trabalho que os donos da natureza inferem valores de mercado à natureza humana e à natureza utilitária. Portanto, não há possibilidades de separação entre os problemas ditos 
ecológicos e as desigualdades socioambientais historicamente construídas pelas relações de exploração dos homens entre si e com a natureza.

A proposta de Educação do Campo está fortemente vinculada a um novo modelo de desenvolvimento para o campo; um desenvolvimento social, economicamente justo e ecologicamente sustentável. No Decreto de № 7.352, de 4 de novembro de 2010 que dispõe sobre a política de educação do campo, 0 artigo $2^{\circ}$ trata dos princípios da educação do campo, e entre os princípios no item do II está o desenvolvimento social, economicamente justo e ambientalmente sustentável como um dos princípios. Sendo assim, o currículo na educação do campo

deve ter sua base na consideração do campo, suas populações, seu modo de vida e as necessidades de transformações sociais; na consideração da vida concreta do campo, da organização da cultura do campo, dos sujeitos que produzem a vida do campo, dos seus processos migratórios, seu modo de vida, da organização do trabalho e da produção agropecuária, das lutas organizadas dos camponeses (TAFFAREL et. al., 2010, p.189).

Para Fernandes, Cerioloi e Caldart (2009) uma escola do campo necessita de um currículo que considere a relação com o trabalho na terra, como parte da identidade do campo, independente dos rumos profissionais que esse sujeito tomará, pois assim desenvolverá o amor à terra e ao processo de cultivá-la. Portanto, como defende Taffarel et. al. (2010, p. 193), é preciso

Considerar as práticas que caracterizam a vida do campo como uma das dimensões do currículo, pois permite pensar para além dos programas em si mesmos, para além dos limites de uma educação restrita à "sala de aula" e à mera transmissão desarticulada de conteúdos, sem sentido e significado para a vida social.

Nesse sentido, a escola do campo tem um papel muito importante no desenvolvimento das comunidades onde estão inseridas, por isso se faz necessário o ensino contextualizado trabalhando questões relevantes da realidade e capaz de promover uma intervenção sobre a realidade social e ambiental. Portanto, não se fará uma educação adequada ao campo dissociada do debate sobre os modelos de desenvolvimento em disputa na sociedade brasileira, em cujo centro está nossa relação com a natureza. Notase, também no âmbito curricular, uma grande abertura para uma aproximação mais orgânica entre a educação do campo e a Educação Ambiental, pois é no debate sobre outra relação possível da sociedade com a natureza que a Educação Ambiental vem se (re)construindo e, por isso, tem grande contribuição a oferecer às escolas do campo e aos demais espaços de formação. 
Diante do projeto de educação campo forjado pelos movimentos sociais, é preciso partir da identificação das práticas de Educação Ambiental presente nas escolas do campo e avaliar sua real contribuição para as comunidades do campo. Neste estudo, nós apresentamos um diagnóstico da situação da Educação Ambiental e da educação do campo nas escolas de ensino fundamental da Região da Serra da Jibóia-BA, para, a partir disso, refletir sobre os limites e as possibilidades de diálogo entre essas duas áreas no enfrentamento dos problemas socioambientais locais.

\section{Aspectos metodológicos da pesquisa}

\section{A Serra da Jiboia}

A Serra da Jiboia é um maciço serrano situado na porção sul do Recôncavo Baiano, entre os municípios de Castro Alves, São Miguel das Matas, Varzedo, Elísio Medrado e Santa Terezinha (FREITAS; MORAES, 2009, p.1). A região está inserida no bioma Mata Atlântica e abriga o maior remanescente florestal da região do Recôncavo Sul Baiano, responsável pela formação de importantes bacias hidrográficas da região e detentor de uma rica diversidade de plantas e animais. esta serra tem uma extensão de aproximadamente 23.000 hectares ainda cobertos por remanescentes de Mata Atlântica. Porém destes apenas 7.000 hectares está em estágio avançado de regeneração (FREITAS; MORAES, 2009). A população ocupa-se principalmente da agricultura familiar de subsistência, como as monoculturas de mandioca, feijão, milho, banana, laranja, café e fumo.

A Serra da Jiboia foi ocupada pelos índios Kiriri-Sapuyiá que viviam na área do vale do Paraguaçu, denominado por eles de Guariru, que significa lugar de muitas águas. Os Kiriri-Sapuyá formavam um subgrupo Kiriri estabelecido no vale do Paraguaçu, rio que deságua na Baía de Todos os Santos e tem suas nascentes na Chapada Diamantina, ha $300 \mathrm{~km}$ do litoral. Segundo Paraiso (1985) os Kiriri teriam se deslocado no sentido N/S de onde teriam sido expulsos por grupos de origem Tupi para o interior e desde então haveria vagas notícias de sua presença no litoral.

Paraiso (1985) expõe que nos fins do século XVIII e início do século XIX o fumo passa a ser um dos elementos mais importantes da economia baiana devido a sua ampla aceitação no mercado africano. Por isso, passou a demandar mais áreas cultiváveis, empurrando os criadores de gado para as terras indígenas e expulsando os indígenas de seu território original:

É exatamente sobre as terras que antes estavam ocupadas com a criação do gado que o fumo se expande, atingindo indiretamente a aldeia de Pedra Branca, pois os criadores foram empurrados para as terras dos índios; isto levou a sérias convulsões sociais, que se refletiram na vida que essa comunidade dispersa e expulsa de seu território original leva até hoje (PARAISO, 1985, p.23). 
Assim acontece o aldeamento de Pedra Branca com dois núcleos de habitação: Os autores identificaram dois núcleos de habitação, um em Pedra Branca, que seria ocupado pelos Sapuyá, e outro em Caranguejo, onde segundo eles, viviam os Kiriri (PARAISO, 1985, p. 24). Mas ainda permanece um campo de disputas, os índios atacavam os rebanhos para se alimentar, pois o ecossistema local havia sido comprometido pela introdução dos pastos e lavouras de fumo no lugar das florestas. Também nesse momento a população indígena está em número reduzido, sua mão-de-obra já não é mais interessante nas atividades econômicas, e a desistência de seu uso como guias nas expedições para descobertas de metais preciosos ou mesmo no combate a índios mais bravos geraram o desinteresse pelo aldeamento, e suas terras eram vistas como a única forma de aumentar a produção agrícola devido às técnicas rudimentares de exploração: Nesse quadro de disputa pelas terras, agravado pelos choques decorrentes do ataque aos rebanhos locais pelos índios, os Kiriri-Sapuyá marchavam para a fase inicial de sua expulsão das terras da aldeia (PARAISO, 1985, p. 26).

\section{Sujeitos da pesquisa}

A pesquisa foi realizada com os professores das séries iniciais do ensino fundamental que atuam nas 11 escolas do Campo, sendo que seis escolas se encontram no município de Elísio Medrado e cinco no município de Santa Teresinha. Participaram da pesquisa um total de 45 professores, todos residentes em área de Zona Rural que lecionam em suas próprias comunidades. Quanto à formação, 59,09\% possuem apenas ensino médio, $31,82 \%$ possuem o nível superior incompleto, $4,55 \%$ superior completo e $4,55 \%$ são pós-graduados latu sensu.

\section{Coleta dos dados}

Para coletar os dados sobre a EA e EC, foi aplicado um questionário misto, contendo um quadro com informações gerais a respeito do educador, seguido de dez questões das quais cinco eram fechadas e cinco abertas. Das dez questões, oito tratavam da EA e duas da Educação do Campo. Além dos questionários a coleta dos dados foi feita por meio de visitas para observação do cotidiano, análise de documentos, participação em reuniões de planejamento pedagógico e entrevistas abertas com 4 professores de cada município. Os dados brutos produzidos durante a pesquisa, questionários, fotos e textos foram depositados na Coordenação do Programa de Pós-graduação em Educação do Campo e Desenvolvimento Sustentável do Semiárido, no Centro de Formação de Professores da Universidade Federal do Recôncavo da Bahia, no município de Amargosa-BA. Os dados foram analisados de forma quantitativa por meio da frequência com que as categorias se repetiram nos questionários e de forma qualitativa por meio da análise do conteúdo presente nos discursos dos professores. Os dados foram coletados no período de agosto a dezembro de 2012.

revista brasileira educação ambiental 


\section{Resultados e discussão}

\section{A formação em EA e EC dos professores}

A formação em EA dos professores e das professoras das escolas do campo da Serra da Jibóia inseridas nos municípios de Elísio Medrado e Santa Teresinha se mostra ainda deficiente, pois apenas $22,73 \%$ dos professores e professoras fizeram algum tipo de capacitação em EA.

Ao avaliarmos a formação dos professores em Educação do Campo os dados mostram realidades diferentes para os dois municípios. No município de Elísio Medrado $87,50 \%$ dos professores receberam algum tipo de formação em educação do campo. Porém, a formação que receberam foi da Secretaria de educação do município para trabalhar com o programa Escola Ativa do Ministério da Educação. Segundo relato dos professores essa formação foi realizada com o objetivo de apresentar o referido programa aos professores que passariam a aplicá-lo em suas escolas. No entanto, ficou evidente nas entrevistas que tal atividade foi desenvolvida sem uma discussão mais aprofundada sobre o projeto de Educação do Campo que vem sendo construída a partir das lutas sociais travadas pelos homens e mulheres que vivem no campo brasileiro. Em Santa Teresinha a formação dos professores em Educação do campo não aconteceu para $71,43 \%$ dos seus professores. Essa realidade evidencia os desafios para se concretizar o estabelecido no Decreto 7.362/2010 que dispõe sobre a política de Educação do Campo, cujo Art. $4^{\circ}$ preconiza que

A União, por meio do Ministério da Educação, prestará apoio técnico e financeiro aos Estados, ao Distrito Federal e aos Municípios na implantação das seguintes ações voltadas à ampliação e qualificação da oferta de educação básica e superior às populações do campo em seus respectivos sistemas de ensino, sem prejuízo de outras que atendam aos objetivos previstos neste Decreto:

$\mathrm{VI}$ - formação inicial e continuada específica de professores que atendam às necessidades de funcionamento da escola do campo;

Para a formação desse corpo profissional será urgente a interiorização da educação superior ${ }^{3}$ (ARROYO, 2007). Sobre esse aspecto, vários

\footnotetext{
${ }^{3} \mathrm{O}$ enfrentamento do problema de formação docente na região começa a ser enfrentado com a chegada da Universidade Federal da Bahia-UFRB através do Centro de Formação de Professores-CFP que já contribui para qualificação da educação do campo. O CFP vai receber o Curso de Licenciatura em Educação do Campo, já oferece a Pós-Graduação em Educação do Campo em Desenvolvimento Territorial Sustentável e mais recentemente abriu o Mestrado Profissional em Educação do Campo, sendo estas oportunidades de aperfeiçoamento e formação para os professores da Região.
}

Revbea, São Paulo, V.11, № 2: 385-399, 2016. 
professores declararam que no momento de preencherem o questionário fizeram uma auto avaliação sobre seus conhecimentos acerca da EA e EC e viram a necessidade de formação específica. Por isso, durante nossas visitas, os professores solicitaram que a Universidade Federal do Recôncavo da Bahia, por meio do Curso de Pós-Graduação em Educação do Campo e Sustentabilidade do Semiárido organizasse um seminário para debater sobre EA e EA. Conduzimos a ideia, que foi bem acolhida nas reuniões com representantes das secretarias municipais de educação, sindicatos, ONG e igreja. Porém, o período eleitoral, bastante conturbado nessas cidades, terminou por inviabilizar o evento, pois a troca de Prefeitos dificultou uma nova articulação dentro do período desta pesquisa.

Além da baixa escolaridade dos professores, que é um dos grandes problemas que se coloca para a Educação do Campo, outro problema importante a ser enfrentado é a formação urbanocêntrica desses educadores. Estas, por muitas vezes, pouco contribuem para a manutenção do sentimento de pertencimento ao campo. Os resultados obtidos neste estudo corroboram as afirmações de Zakrzevski (2007, p. 203):

Um dos grandes desafios às escolas do campo é contribuir para recriar os vínculos de pertencimento dos sujeitos, para que estes se reconheçam como integrantes de uma comunidade e reconstruam a sua identidade com o campo, com o local em que vivem. No momento em que os sujeitos sentem-se pertencentes a um determinado território, possuem sentimentos que Ihes possibilitam comprometerem-se com a realidade socioambiental respeitando suas potencialidades e seus limites.

O baixo nível de escolaridade encontrado e a ausência de formação adequada à realidade do campo demonstra a carência de políticas públicas voltadas à formação de professores e a urgência do comprometimento dos poderes públicos na formação desses profissionais para atuarem de forma a promover, por meio da educação, o desenvolvimento social justo e sustentável para o campo.

Além da carência de formação inicial e continuada outro problema percebido é que $81,82 \%$ dos professores participantes desta pesquisa possuía vínculo empregatício temporário. Dessa forma, os municípios pesquisados ilustram uma realidade ainda presente na maioria dos municípios do interior do Estado em que, a cada quatro anos, o quadro de professor é modificado por conta de novas contratações da nova Gestão municipal. Essa realidade compromete o investimento na formação desses profissionais da educação e atinge especialmente as escolas das zonas rurais. "Sem a conformação de um corpo profissional estável todo esforço de formação específica se perde" (ARROYO, 2007, p. 170). Os prejuízos para a efetivação da EA e da EC são muitos uma vez que o professor e a escola ficam refém das forças políticas locais.

revista brasileira educação ambiental 


\section{A Educação Ambiental praticada nas escolas dos municípios pesquisados}

Todos os professores pesquisados afirmaram que a EA é desenvolvida nas escolas e que esta é trabalhada inserida nas disciplinas, confirmando o que Veiga (2005) também constatou para o nível nacional. Como forma de avaliar os efeitos da EA trabalhada pela escola, utilizamos como indicador a destinação final do lixo produzido na escola. Observamos que $75 \%$ das escolas do campo pesquisadas na Serra ainda queimam o lixo gerado, demonstrando, portanto, uma prática contraditória aos princípios orientadores da EA.

Ao analisarmos se a EA está oficialmente inserida no Projeto Pedagógico da escola $59,09 \%$ dos professores pesquisados afirmaram que sim enquanto que $31,82 \%$ não souberam responder ou não conheciam o documento, fundamental no direcionamento das atividades na escola. Para Zakrzevski (2004) não basta a EA estar inserida nos documentos oficiais da escola, mas ela deve estar vinculada às causas, aos desafios, aos sonhos, à história e à cultura dos povos que vivem no meio rural.

Quanto ao desenvolvimento de Projetos educacionais em EA das escolas, os municípios estudados apresentaram diferentes realidades. No município de Elísio Medrado $75 \%$ dos professores afirmaram participar de Projetos de EA na escola. Destes professores 33,3\% afirmaram que o objetivo do projeto foi "conscientizar para a preservação das árvores para que não falte água". Outros $33,3 \%$ dos professores participaram do projeto que teve como objetivo a "Preservação do meio ambiente"; $16,7 \%$ dos professores participaram do projeto que resumiram como objetivo o "Reflorestamento da praça da Comunidade" e os outros $16,7 \%$ participaram de um projeto que teve como objetivo "Recuperação de espaços desmatados". Em Santa Teresinha pouco mais da metade dos professores $(53,85 \%)$ afirmaram não ter participado de projetos de EA na escola. Porém dos que participaram $(46,15 \%)$, metade não resumiu o objetivo enquanto $16,6 \%$ resumiram o objetivo do projeto como "Preservar e reutilizar", outros $16,6 \%$ dos professores teve como objetivo do projeto que participaram "Conscientizar sobre o uso da água e o desmatamento" e outros $16,6 \%$ "Implantação de cercas-vivas nas escolas e a adoção de uma árvore por cada aluno". Esses dados estão organizados na Tabela 1.

A utilização de projetos em Educação Ambiental se mostra como uma estratégia interessante, pois contribui na problematização da realidade, permite uma releitura de sua realidade a partir de novos olhares sobre ela e permite explicitar os conflitos socioambientais presentes no local favorecendo assim a percepção crítica e reflexiva do ambiente do qual o educando é parte integrante. Porém, alguns projetos citados pelos professores foram atividades realizadas por uma ONG ambientalista da região em parceria com estas escolas, o que não se constituem projetos de Educação Ambiental de iniciativa dessas escolas. Mais uma vez, fica demonstrada a necessidade de formação 
desses professores na construção e execução de projetos escolares em Educação Ambiental.

Tabela 1: Participação dos professores das escolas rurais do entorno da Serra da Jibóia-BA em projetos de Educação Ambiental.

\begin{tabular}{|c|c|c|c|}
\hline Município & $\begin{array}{l}\text { Participantes de } \\
\text { Projetos de EA }\end{array}$ & Objetivos dos projetos & Frequência \\
\hline \multirow{4}{*}{$\begin{array}{l}\text { Elísio } \\
\text { Medrado }\end{array}$} & \multirow{4}{*}{$75 \%$} & $\begin{array}{l}\text { Conscientizar para a preservação das } \\
\text { árvores para que não falte água }\end{array}$ & $35 \%$ \\
\hline & & Preservação do meio ambiente & $33 \%$ \\
\hline & & Reflorestamento da praça da Comunidade & $17 \%$ \\
\hline & & Recuperação de espaços desmatados & $15 \%$ \\
\hline \multirow{4}{*}{$\begin{array}{l}\text { Santa } \\
\text { Teresinha }\end{array}$} & \multirow{4}{*}{$46,15 \%$} & Preservar e reutilizar & $19 \%$ \\
\hline & & $\begin{array}{l}\text { Conscientizar sobre o uso da água e o } \\
\text { desmatamento }\end{array}$ & $15 \%$ \\
\hline & & $\begin{array}{l}\text { Implantação de cercas-vivas nas escolas e a } \\
\text { adoção de uma árvore por cada aluno }\end{array}$ & $13 \%$ \\
\hline & & Não souberam informar & $53 \%$ \\
\hline
\end{tabular}

A Serra da Jiboia não está entre os temas mais abordados nas atividades de EA, pois apenas $12,5 \%$ dos professores a citou como tema de suas aulas, e nem a sua degradação foi citada como um dos problemas que os professores consideravam o maior desafio para a EA na atualidade na escala se seus municípios ou na Região do Recôncavo da Bahia (Tabela 2).

Tabela 2: Problemas eleitos pelos professores como o maior desafio da EA nas diferentes escalas.

\begin{tabular}{|c|c|c|c|}
\hline MUNICÍPIO & $\begin{array}{l}\text { ESCALA } \\
\text { ESPACIAL }\end{array}$ & $\begin{array}{l}\text { PRINCIPAL PROBLEMA A } \\
\text { SER ENFRENTADO }\end{array}$ & $\begin{array}{l}\text { FREQUÊNCIA } \\
\text { DAS } \\
\text { RESPOSTAS }\end{array}$ \\
\hline \multirow{2}{*}{ Santa Teresinha } & Para as escolas & Falta de Coleta de Lixo & $54,5 \%$ \\
\hline & Para o município & Coleta de lixo & $45,4 \%$ \\
\hline \multirow{2}{*}{ Elísio Medrado } & Para as escolas & Falta de água & $60 \%$ \\
\hline & Para o município & Seca & $60 \%$ \\
\hline \multirow[t]{2}{*}{ Ambos } & $\begin{array}{l}\text { Para a região do } \\
\text { Recôncavo da Bahia }\end{array}$ & Desmatamento & $43,7 \%$ \\
\hline & Nível global & Poluição & $56,25 \%$ \\
\hline
\end{tabular}

É imprescindível que as questões socioambientais da Serra da Jiboia sejam trabalhadas nas escolas dos municípios para que conheçam a sua história (através de livros, mas também a contada pelos mais antigos da comunidade), seus aspectos geográficos, sua cultura (pois esta está ligada aos elementos do ambiente), riqueza biológica bem como os conflitos, históricos e atuais decorrentes do uso da natureza. É a partir dessas ações de ensino que será desenvolvido o "sentimento de pertencimento ao meio $e$ de 
responsabilidade por ele, pois conhecer e compreender o meio em que se vive $e$ as inter-relações entre os diferentes elementos que o compõem é condição essencial para a conservação da diversidade biológica e cultural de um território" (ZAKRZEVSKI, 2007, p. 203).

O objetivo principal da EA para $68,2 \%$ dos professores dos municípios de Elísio Medrado e Santa Teresinha seria "Conscientizar para a preservação do Meio Ambiente". Para 13.6\% desses professores seria "Conscientizar da importância do ambiente", enquanto 4,5\% resumiram como objetivo a "Melhor condição de vida para os seres vivos" e outros $4,5 \%$ "Como tratar o lixo". Não responderam a essa questão $4,5 \%$ dos professores pesquisados. Os objetivos citados mostram uma EA voltada para a transmissão de conteúdos e sensibilização dos educandos quanto ás questões ambientais visando à mudança de comportamento em relação ao meio ambiente entendido apenas como os aspectos físicos, ao que Carvalho (2001) definiu de EA comportamental. Para a autora, nessa concepção "[...] é valorizado o papel da educação como agente difusor dos conhecimentos sobre o meio ambiente e indutor da mudança dos hábitos e comportamentos considerados predatórios, em hábitos e comportamentos tidos como compatíveis com a preservação dos recursos naturais" (CARVALHO, 2001, p.46).

Na utilização do termo "Conscientização" é observada uma distância conceitual daquele ensinado por Paulo Freire (2001, p. 15), pois, segundo este

a tomada de consciência não é ainda a conscientização, porque esta consiste no desenvolvimento crítico da tomada de consciência. A conscientização implica, pois, que ultrapassemos a esfera espontânea de apreensão da realidade, para chegarmos a uma esfera crítica na qual a realidade se dá como objeto cognoscível e na qual o homem assume uma posição epistemológica.

A conscientização é, neste sentido, um teste de realidade. Quanto mais conscientização, mais se "desvela" a realidade, mais se penetra na essência fenomênica do objeto, frente ao qual nos encontramos para analisá-lo. Por esta mesma razão, a conscientização não consiste em "estar frente à realidade" assumindo uma posição falsamente intelectual. A conscientização não pode existir fora da "práxis", ou melhor, sem o ato ação - reflexão. Esta unidade dialética constitui, de maneira permanente, o modo de ser ou de transformar o mundo que caracteriza os homens.

Portanto, a conscientização proposta nas atividades de Educação Ambiental que tem como meta a sensibilização dos sujeitos para que mudem seu comportamento, passando agora à proteção da natureza de forma a não interferir em seu curso está distante do que Zakrzevski (2004) defende para os povos do campo. A Educação Ambiental naturalista/comportamental tem sua 
práxis fundada no conceito de homens e mulheres como produto da natureza, que deve ser protegida do homem que a explora e a maltrata. Assim, há uma tentativa de reinserção em seu lugar de origem, de forma que ele se identifique com ela e a preserve. No entanto, partindo da tese de Marx, o homem é produto da história, não da natureza. Conforme explica Bernard Charlot (2013, p. 236)

a história da espécie humana é, antes de tudo, uma longa luta para sobreviver, o que implica o confronto coletivo com a Natureza através do trabalho. O homem transforma a Natureza por seu trabalho e, ao fazê-lo, transforma, também, a si mesmo; esse processo é que Marx nomeia de práxis. Sob outra forma, o homem não é produto da Natureza, é produto do trabalho sob a natureza.

Partindo desta tese, a práxis da EA para as escolas do campo deverá considerar a cultura historicamente construída pelos camponeses, frutos de seus trabalhos para sobrevivência na lida cotidiana com a natureza. Por isso, deve visar a formação de sujeitos politizados, capazes de atuar de forma crítica diante das questões socioambientais, sendo, assim, mais efetiva no alcance do grande desafio que está posto para a escola do campo. Ao explicitar os conflitos socioambientais e permitir o diálogo, a EA cria condições para que os sujeitos desenvolvam uma visão mais completa sobre a realidade local, se localize e se posicione diante do problema. Nesse aspecto, os resultados obtidos junto às escolas da Serra da Jiboia evidencia a necessidade de se construir maiores diálogos entre a EA e EC, pois ambas buscam um desenvolvimento social, justo e sustentável baseado no entendimento da complexidade do ambiente, do respeito a todas as formas de vida e na igualdade de direitos. Mais uma vez nos apropriamos do pensamento de Zakrzevski (2004) para ilustrar como essas áreas da educação estão intrinsecamente relacionadas e como seus projetos são convergentes:

O grande desafio, hoje, colocado à educação do campo está na necessidade de estimular um processo de reflexão sobre modelos de desenvolvimento rural que sejam responsáveis, economicamente viáveis e socialmente aceitáveis, que colaborem para a redução da pobreza, para a conservação dos recursos naturais e da biodiversidade, para a resolução dos problemas ambientais, fortalecendo as comunidades que vivem no campo, não dissociando a complexidade da sociedade e da natureza. (ZAKRZEVSKI, 2004, p.85).

Uma das principais características da EC e da EA é a participação ativa da comunidade na vida escolar. A participação da comunidade está assim colocada no Decreto 7.362/2010 que dispõe sobre a política de Educação do Campo como um dos princípios da Educação do Campo: 
Art. $2^{\circ}$ São princípios da educação do campo:

II - incentivo à formulação de projetos político-pedagógicos específicos para as escolas do campo, estimulando o desenvolvimento das unidades escolares como espaços públicos de investigação e articulação de experiências e estudos direcionados para o desenvolvimento social, economicamente justo e ambientalmente sustentável, em articulação com o mundo do trabalho;

$\mathrm{V}$ - controle social da qualidade da educação escolar, mediante a efetiva participação da comunidade e dos movimentos sociais do campo.

A ação conjunta com a comunidade favorece o desenvolvimento social, e a Educação Ambiental do campo ao contribuir na relação de colaboração da escola com a comunidade cria espaços para a aprendizagem coletiva por meio do diálogo e da cooperação. No entanto, nas escolas estudadas do município de Elísio Medrado apenas um professor citou a participação da comunidade em atividades de Educação Ambiental enquanto que em Santa Teresinha ocorreram 4 citações. Em Santa Teresinha as ONGs também foram citadas por 3 professores como atores envolvidos em projetos de EA. Portanto, os dados demonstram uma falta de articulação da escola com as entidades que atuam na região e dentro da própria comunidade. Nota-se, com isso, a necessidade de se fortalecer os vínculos da comunidade escolar com os parceiros potenciais que atuam na região, entre os quais citam-se: Sindicatos de Trabalhadores e Trabalhadoras Rurais-STTR, Empresa Baiana de Desenvolvimento Agrícola-EBDA, Grupo Ambientalista da Bahia-GAMBÀ, Secretaria Municipal de Agricultura e Meio Ambiente, Universidade Federal do Recôncavo da Bahia. Dessa forma, a realidade observada neste estudo confirma a preocupação do Ministério da Educação de que "ainda existe um enorme caminho para avançar na relação escola-comunidade" (BRASIL, 2007, p. 21). É por meio do diálogo entre os membros da escola e destes com as pessoas e organizações da comunidade e através da reflexão crítica da realidade social que a eles se apresentam que se dá o processo de aprendizagens coletivas e a construção de saberes, atitudes e valores que enriquecem escola e comunidade e espaço para construção de projetos a serem desenvolvidos na comunidade a partir das demandas da mesma.

\section{Percepção dos professores sobre a educação do campo}

Os dois municípios estudados apresentam realidades diferentes quanto à adequação do Projeto Político Pedagógico-PPP ás especificidades do campo. Todos os professores de Elísio Medrado afirmaram que os PPPs das escolas contemplam adequadamente as especificidades da educação do campo enquanto que em Santa Teresinha esse percentual foi de $46 \%$. No entanto, é possível perceber algumas contradições nas respostas dos 
professores, pois nas escolas pesquisadas não foi observada organização escolar própria às práticas além da inadequação do calendário escolar às fases do ciclo agrícola e climáticas. Segundo relato de alguns professores a seca de 2012 provocou a evasão escolar, pois os alunos precisavam ajudar as famílias na luta para conseguir água e manter seus cotidianos. Quanto à adequação à natureza do trabalho na zona rural também não foi observada nenhuma mudança na rotina das escolas embora $23,8 \%$ dos professores de Elísio Medrado e $17,39 \%$ dos professores de Santa Teresinha afirme a inclusão dessa perspectiva no PPP.

Ao participarmos das reuniões para construção do Plano Municipal de Educação-PME do município de Santa Terezinha percebemos um desconhecimento acerca das Diretrizes Operacionais das escolas do campo, o que explica a falta de adequação dessas escolas a realidade do campo. A concepção de Educação do Campo por parte dos professores foram as mais diversas possíveis. No entanto, duas apareceram de forma mais expressivas entre os professores que apontam para um horizonte fértil para a relação entre a Educação Ambiental e a educação do campo. Ao discursar sobre a educação do campo, a "Preservação e cuidado com o meio ambiente" apareceu no discurso de $37,5 \%$ dos professores de Santa Teresinha. A concepção de que se trata de uma "Proposta pedagógica apropriada às reais necessidades e interesses dos alunos do campo" foi citada por $31,25 \%$ dos professores presentes ao encontro. Embora ainda reflita uma compreensão simplificada em função da concepção reducionista de meio ambiente consideramos fértil por essa vir acompanhada da preocupação com as especificidades dos alunos do campo. No entanto, fica exposta a distância para a compreensão da Educação Ambiental e da educação do campo como conquistas das lutas sociais contra o modelo de desenvolvimento brasileiro que tem colocado o campo como lugar de atraso.

\section{Considerações finais}

Todos os professores participantes do presente estudo afirmaram trabalhar a EA inserida nas disciplinas e em projetos. Porém, a EA tem sido trabalhada de forma ingênua, descontextualizada da realidade do campo e não problematizadora, sem compreender as questões socioambientais da Serra da Jiboia em sua complexidade. Nesse contexto, Lixo e reciclagem, preservação ambiental e água são os temas mais trabalhados em atividades de EA, todos desconectados dos processos sociais, culturais, econômicos e políticos que tem marcado a história tanto da Serra da Jiboia quanto das escalas regional e Global. Aqui, fica exposta uma concepção de EA naturalista/comportamental que busca reproduzir nos sujeitos comportamentos ambientalmente corretos, distante, portanto, do projeto de educação do campo protagonizado pelos movimentos sociais, ou seja, uma EA que promova a formação de sujeitos politizados capazes de atuar de forma crítica diante das questões socioambientais que a ele se apresenta. Nesse contexto, para que essa EA se efetive, a relação escola-comunidade precisa avançar na Região da Serra da

revista brasileira educação ambiental 
Jiboia, pois está fragilizada pela falta de articulação das instituições escolares com a comunidade em geral e com instituições parceiras potenciais.

Ao avaliarmos a EC que tem sido praticada por essas escolas, vemos o quanto as populações do campo desses municípios têm sido privados de uma educação contextualizada e voltada aos seus interesses. Poucos esforços foram notados quanto à adoção de medidas específicas por estas escolas para atender as populações do campo sendo as concepções de EC dos educadores ainda simplistas diante do processo de formação humana integral a que se propõe esta educação.

Fernandes (2015, p. 8) afirma que "a luta pela Educação do Campo apresenta ampla dimensão com expectativas de progresso para além da escola e com possibilidades para transformações das condições de vida no campo". A deficiência de formação básica dos professores associada à ausência de uma formação para a compreensão dos princípios e objetivos da EA e EC, se apresenta como um problema que deve ser o quanto antes superado. Tal realidade compromete o desenvolvimento de uma educação contextualizada e de qualidade nas escolas do campo na Região da Serra da Jiboia, onde a relação homem-natureza já sente os efeitos degradantes do modelo hegemônico de desenvolvimento social e econômico. Nesse aspecto, a Educação Ambiental tem construído um discurso bastante amadurecido e afinado com os princípios do projeto de educação do campo construído pelos movimentos sociais que juntos, poderão construir uma nova forma de convivência das comunidades com a natureza na Região da Serra da Jiboia.

\section{Referências}

ARROYO, M. G. Políticas de formação de educadores(as) do campo. Caderno CEDES, Campinas, V. 27, n. 72, p.157-176, 2007. Disponível em: http://www.cedes.unicamp.br

BRASIL. Ministério da Educação. A implantação da Educação Ambiental no Brasil. Brasília: MEC, 1998. Disponível em: 10 de setembro de 2012. Acessado em:<http://www.dominiopublico.gov.br/download/texto/me001647.pdf>

BRASIL. Ministério da Educação. Cadernos Secad 1. Educação Ambiental: aprendizes de sustentabilidade. Brasília, 2007.

BRASIL. Ministério da Educação. Cadernos Secad 2. Educação do campo: diferenças mudando paradigmas. Brasília, 2007.

CALDART, R. C. Por uma educação do campo: traços de uma identidade em construção. In: ARROYO, M., CALDART, R.S.; MOLINA, M.C. (Orgs). Por uma Educação do Campo. 4ª Ed. Petrópolis, RJ: Vozes, 2009.

CARVALHO, I.C.M.; FARIAS, C.R.O. Um Balanço da Produção Científica em Educação Ambiental de 2001 a 2009 (ANPEd, ANPPAS e EPEA). Revista Brasileira de Educação. V. 16, N. 46. Janeiro/abril de 2011. 
CHARLOT, B. Da relação com o saber às práticas educativas. São Paulo. Cortez. 2013.

FERNANDES, B.M.; CERIOLI, P. R.; CALDART, R. S. Primeira Conferência Nacional "Por Uma Educação Básica do Campo": texto preparatório. In: ARROYO, M., CALDART, R.S.; MOLINA, M.C. (Orgs). Por uma Educação do Campo. 4르. Ed. Petrópolis, RJ: Vozes, 2009.

FERNANDES, I.L. A construção de políticas púbicas de educação do campo através das lutas dos movimentos sociais. Revista lugares de educação. Bananeiras/PB, v. 4, n. 8, p. 125-135. 2014

FREIRE, P. Conscientização - Teoria e Prática da Libertação: uma introdução ao pensamento de Paulo Freire. São Paulo: Centauro, 2001.

FREITAS, M.A.; MORAES, E.P.F. Levantamento da avifauna da Fazenda Jequitibá (Serra da Jibóia), município de Elísio Medrado/Bahia. Atualidades Ornitológicas On-line, oㅡ 147, jan/fev. 2009. Disponível em: www.ao.com.br. Acesso em: 01/11/12.

MOLINA, M.C. (Org.). Educação do Campo e Pesquisa II: questões para reflexão. Brasília, MDA/MEC, 2010.

PARAISO, M. H. B. Os Kiriri Sapuyá de Pedra Branca. UFBA. Universidade Federal da Bahia. Centro de Estudos Baianos. Salvador, 1985.

SAVIANI, D. Pedagogia Histórico-Crítica: primeiras aproximações. 4aㅡ Ed. Campinas, SP: Autores Associados, 1944.

TAFFAREL, C.Z.; ESCOBAR, M.O.; PERIN, T.F. Currículo. In: UFBA. Universidade Federal da Bahia. TAFFAREL, C.N.Z. et al. (org.). Cadernos didáticos sobre educação no campo. Salvador: Editora, 2010.

VEIGA, A.; AMORIM, E.; BLANCO, M. Um Retrato da Presença da Educação Ambiental no Ensino Fundamental Brasileiro: o percurso de um processo acelerado de expansão. Brasília-DF, Instituto Nacional de Estudos e Pesquisas Educacionais Anísio Teixeira, 2005. Disponível em: http://www.inep.gov.br/publicacoes

ZAKRZEVSKI, S.B. Por uma Educação Ambiental crítica e emancipatória no meio rural. Revista Brasileira de Educação Ambiental, Brasília, v. 1, n. 0, p. 79-86, 2004.

ZAKRZEVSKI, S.B. A Educação Ambiental nas escolas do campo. In: BRASIL. Ministério da Educação. Vamos cuidar do Brasil: conceitos e práticas em Educação Ambiental na escola. Brasília: MEC, 2007. 